\title{
KINETICS AND MECHANISM OF THE HYDROGEN- EVOLUTION REACTION ON MERCURY IN HCl-DIMETHYLSULPHOXIDE SOLUTIONS
}

\author{
D. Posadas and A. J. Arvía \\ División Electroquímica, Instituto de Investigaciones Fisicoquímicas Teóricas y Aplicadas, \\ Facultad de Ciencias Exactas, Universidad Nacional de La Plata, La Plata, Argentina
}

(Received 21 January 1972)

\begin{abstract}
Rapid galvanostatic and potentiostatic stationary $E / I$ curves, $E /$ time characteristics at current interruption and electrode capacitance measurements were made to investigate hydrogen-ion discharge on mercury in $\mathrm{HCl}-\mathrm{DMSO}$ solutions, with and without the addition of $\mathrm{LiCl}$ as supporting electrolyte. Kinetic parameters and their temperature and concentration dependences are discussed in terms of the initial electron-transfer reaction as rate-determining.
\end{abstract}

\section{INTRODUCTION}

The hydrogen-evolution reaction on mercury in aqueous solutions has been the subject of many publications, which have been compiled by Vetter[1], but the reaction in non-aqueous systems has not been investigated in such a way as to establish its reaction mechanism. There is a report about the polarographic wave of hydrogen discharge on the dme, from $\mathrm{HCl}$ dissolved in dimethylsulphoxide, where an estimation of the diffusion coefficient for the solvated hydrogen ion is made[2], and some publications on the hydrogen-electrode reaction in other solvents, such as acetonitrile and mixtures of acetonitrile and water $[3,4]$.

This reaction has been investigated in this laboratory using $\mathrm{HCl}-D M S O$ solutions on different metals, such as platinum[5, 6], iron[7] and nickel[8]. The reaction mechanism for these metals contains formally the reaction steps which have been discussed in detail for aqueous systems.

The present work comprises the study of $\mathrm{HCl}-$ DMSO solutions on $\mathbf{H g}$-pool and dropping $\mathbf{H g}$ electrodes. These electrodes have been successfully employed in aqueous solutions[9]. $\mathrm{LiCl}$ was chosen as supporting electrolyte because of its high solubility and the existing physicochemical data on LiCl-DMSO solutions.

\section{EXPERIMENTAL TECHNIQUE}

A conventional three-compartment Pyrex-glass cell was used. The Hg-pool working electrode was replaced after each run to minimize the solution creeping at the $\mathrm{Hg} / \mathrm{glass}$ interphase and $\mathrm{Hg}$ contamination[10]. The area of the electrode was
$2.54 \mathrm{~cm}^{2}$. An aqueous sce reference and a Pt counterelectrode were used.

DMSO (Baker a.r.) with a water content of 0.02 per cent was used as received and checked by the Karl Fischer method. LiCl (Merck, a.r.) was dried under vacuum before use. The method for $\mathbf{H g}$ purification was the same as that already described[11]. The preparation of the solutions was made as described elsehwere[12]. Solutions of $\mathrm{HCl}$ with $\mathrm{LiCl}$ as supporting electrolyte in the concentration range of $2 \times 10^{-3} \mathrm{M}$ to $0.5 \mathrm{M}$ at total ionic strength of 0.5 were employed. Solutions were either $\mathrm{H}_{2}$ - or $\mathrm{N}_{2}$-saturated. These gases were purified by passing them through a dry, lubricant-free system, as described before[11]. Experiments were performed within the temperature range 25 to $55^{\circ} \mathrm{C}$, both under galvanostatic and potentiostatic conditions. The cathodic overvoltage decay was recorded with conventional procedure. The electrode capacitance measurements were performed on a dme using an improved version of Grahame's method, as described previously[11].

In most of the runs the rapid-polarization galvanostatic technique was used and owing to the instability of the points the applied potential was changed in a decreasing direction[13]. Faster and better readings were obtained in this fashion. The average currents were between $5 \times 10^{-5}$ to $1 \times 10^{-2} \mathrm{~A}$, the upper limit being safe against the occurrence of undesirable side reactions in the $\mathrm{HCl}-\mathrm{DMSO}$ medium. Potentiostatic $E / I$ curves were also recorded. The ohmic or pseudo-ohmic drops were measured by means of the well-known galvanostatic step method. The pseudoohmic resistance varied from one run to the other; it was between 8 and $15 \pm 2 \Omega$. 


\section{RESULTS}

The hydrogen gas yield

The yield of hydrogen gas was determined by weighing it as $\mathrm{H}_{2} \mathrm{O}$ after its oxidation in a $\mathrm{CuO}$ furnace at $400^{\circ} \mathrm{C}$. The $\mathrm{H}_{2}$ gas was removed from the electrolysis cell by means of $\mathrm{N}_{2}$ gas passed through for $24 \mathrm{~h}$ after current interruption. At $0.46 \mathrm{~mA} / \mathrm{cm}^{2}$, the constant-current hydrogen gas yield was 96.8 per cent. Thus, the over-all reaction can be expressed as

$$
2 \mathrm{H}^{+} \text {(solv) }+2 \mathrm{e} \longrightarrow \mathrm{H}_{2}(\mathrm{~g})
$$

\section{The rest potential}

The initial rest potential, $E_{r}{ }^{1}$, was measured against a sce at different $\mathrm{HCl}$ concentrations and temperature (Table 1). The final rest potentials obtained

Table 1. Rest Potentials

\begin{tabular}{|c|c|c|c|c|}
\hline$\underset{\mathrm{M}}{c_{\mathrm{HCl}}}$ & $\underset{\mathbf{M}}{c_{\text {LICI }}}$ & $\underset{{ }^{\circ} \mathrm{C}}{\text { Temp }}$ & $\underset{\mathrm{V}}{E_{\mathrm{r}}^{1}}$ & $E_{\mathrm{V}}^{\mathrm{t}}$ \\
\hline $2 \times 10^{-3}$ & 0.5 & 25 & -0.362 & - \\
\hline \multirow[t]{2}{*}{$5 \times 10^{-3}$} & 0.5 & $\begin{array}{l}25 \\
35\end{array}$ & $\begin{array}{l}-0.385 \\
-0.375\end{array}$ & - \\
\hline & & 45 & -0.375 & -0.385 \\
\hline \multirow[t]{2}{*}{$2 \times 10^{-2}$} & 0.5 & $\begin{array}{l}28 \\
37\end{array}$ & $\begin{array}{l}-0.382 \\
-0.385\end{array}$ & $\begin{array}{l}-0.400 \\
-0.390\end{array}$ \\
\hline & & 47 & -0.367 & -0.375 \\
\hline \multirow[t]{4}{*}{$0 \cdot 1$} & 0.4 & 25 & -0.368 & - \\
\hline & & $\begin{array}{l}25 \\
25\end{array}$ & $\begin{array}{l}-0.395 \\
-0.370\end{array}$ & $\begin{array}{l}-0.400 \\
-0.380\end{array}$ \\
\hline & & 35 & -0.375 & _ \\
\hline & & 45 & $-0 \cdot 400$ & - \\
\hline \multirow[t]{4}{*}{0.5} & - & 25 & -0.318 & -0.345 \\
\hline & & 25 & -0.335 & - \\
\hline & & 25 & $-0-323$ & - \\
\hline & & 25 & -0.310 & - \\
\hline
\end{tabular}

after electrolysis, $E_{\mathrm{r}}{ }^{\mathrm{r}}$, are also assembled in the Table. These are slightly more negative than $E_{\mathrm{r}}{ }^{\prime}$. Except for the solution which contained no $\mathrm{LiCl}$, no particular concentration effects on $E_{\mathrm{r}}{ }^{1}$ and $E_{\mathrm{r}}{ }^{\mathrm{f}}$ were noticed.

\section{The current/voltage curves}

Figure 1 shows one potentiostatic and one galvanostatic $E / I$ curve obtained with a $0.5 \mathrm{M} \mathrm{HCl}$ solution at $25^{\circ} \mathrm{C}$. The former exhibits at low potentials a cathodic current maximum of the order of $450 \mu \mathrm{A}$. In the potential range from -0.40 to -0.60 $\mathrm{V}$, a constant current of $c a 100 \mu \mathrm{A}$ is observed. At potentials more cathodic than $-0.65 \mathrm{~V}$, a Tafel region is obtained involving an initial slope close to $2 \cdot 3(2 R T / F)$. At higher current the slope tends to increase because of pseudo-ohmic polarization. The

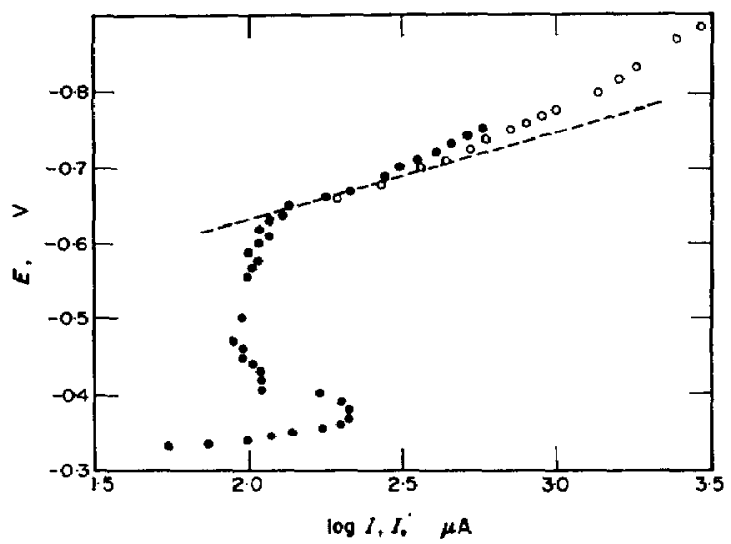

Fig. 1. Semilogarithmic plots of $E / I$ curves without the correction for the pseudo-ohmic polarisation. Dotted line corresponds to a slope $2 \cdot 3(2 R T / F) \cdot 0 \cdot 5 \mathrm{M} \mathrm{HCl} ; 25^{\circ} \mathrm{C}$.

$O$, potentiostatic, $E_{\text {rest }}=-0.323 \mathrm{~V}$ (sce); $O$, galvanostatic, $E_{\mathrm{rest}}=-0.310 \mathrm{~V}($ sce $)$.

galvanostatic $E / I$ curve reproduces the Tafel line region of the potentiostatic curve.

The maximum cathodic current at low cathode potentials has been also recorded in polarographic experiments with $\mathrm{HCl}-\mathrm{DMSO}$ solutions containing $\mathrm{LiCl}$ as supporting electrolyte (Fig. 2).

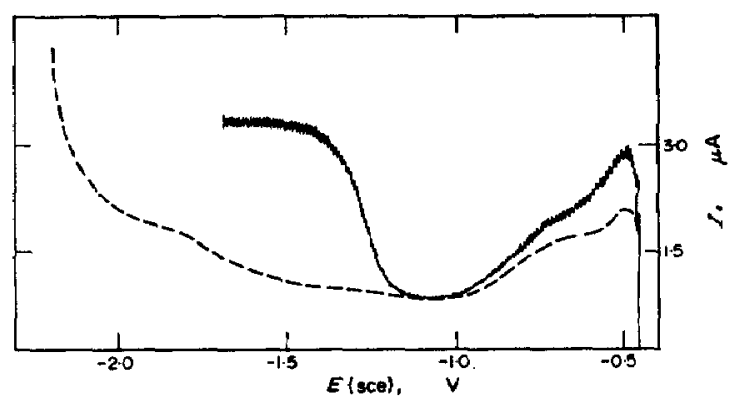

Fig. 2. Polarogram of a $2 \times 10^{-3} \mathrm{M} \mathrm{HCl}+0.5 \mathrm{M} \mathrm{KClO}_{4}$ solution at $18^{\circ} \mathrm{C}$. Dotted line corresponds to a blank at $35^{\circ} \mathrm{C}$. $t$ (open circuit), $2.06 s ; m, 3.3 \times 10^{-3} \mathrm{~g} / \mathrm{s} ; \mathrm{d} E / \mathrm{d} t$, $0.05 \mathrm{~V} / \mathrm{min}$.

Galvanostatic cathodic $E / I$ curves recorded at constant ionic strength and different hydrogen-ion concentration and temperature are plotted as $E / \log I$ relationships in Fig. 3, after correction for the pseudoohmic polarization. Tafel slopes obtained from the $E / I$ plots are assembled in Table 2. They are close to $2 \cdot 3(2 R T / F)$, as in the cases previously described. The $i_{0}$ values referred in the Table are extrapolated at the rest potentials. Those potentials, as reported further on, are quite close to the pzc of the $\mathrm{Hg}$ electrode in these solutions. Unfortunately the complex and rather irreproducible initial behaviour of the $E / I$ curves at low cathode potentials makes it 
Table 2. Kinetic parameters derived from current/potential curves

\begin{tabular}{|c|c|c|c|c|c|c|}
\hline $\begin{array}{c}c_{\mathrm{HC1}} \\
\mathbf{M}\end{array}$ & $c_{\mathbf{M} 1 \mathrm{Cl}}$ & $\underset{{ }^{\prime} \mathrm{C}}{\text { Temp }}$ & $\underset{\mathbf{V}}{(\Delta E / \Delta \log i)_{c}}$ & $\underset{\mathrm{V}}{2 \cdot 3(2 R T / F)}$ & $\begin{array}{c}\log i_{0} \\
\left(i_{0} \text { in } \mathrm{A} / \mathrm{cm}^{2}\right)\end{array}$ & $\begin{array}{r}\Delta H_{n=0}^{*} \\
\mathrm{kcal} / \mathrm{mole}\end{array}$ \\
\hline $0.5 \times 10^{-2}$ & 0.5 & $\begin{array}{l}25 \\
35 \\
45\end{array}$ & $\begin{array}{l}0.112 \\
0.126 \\
0.135\end{array}$ & $\begin{array}{l}0.118 \\
0 \cdot 122 \\
0.126\end{array}$ & $\begin{array}{r}-9.923 \\
-9.473 \\
-9.148\end{array}$ & $18 \cdot 7$ \\
\hline $0.2 \times 10^{-1}$ & 0.5 & $\begin{array}{l}28 \\
37 \\
47\end{array}$ & $\begin{array}{l}0.121 \\
0.117 \\
0.114\end{array}$ & $\begin{array}{l}0.119 \\
0.123 \\
0.127\end{array}$ & $\begin{array}{r}-9.513 \\
-9.293 \\
-8.993\end{array}$ & $12 \cdot 8$ \\
\hline $0 \cdot 1$ & $0 \cdot 4$ & $\begin{array}{l}25 \\
35 \\
45\end{array}$ & $\begin{array}{l}0 \cdot 112 \\
0 \cdot 108 \\
0 \cdot 103\end{array}$ & $\begin{array}{l}0.118 \\
0.122 \\
0.126\end{array}$ & $\begin{array}{r}-8 \cdot 723 \\
-8.373 \\
-8 \cdot 073\end{array}$ & $16 \cdot 0$ \\
\hline 0.5 & & 25 & 0.130 & 0.118 & $-7 \cdot 500$ & - \\
\hline
\end{tabular}

* The estimated error for the Tafel slope is about 15 per cent.

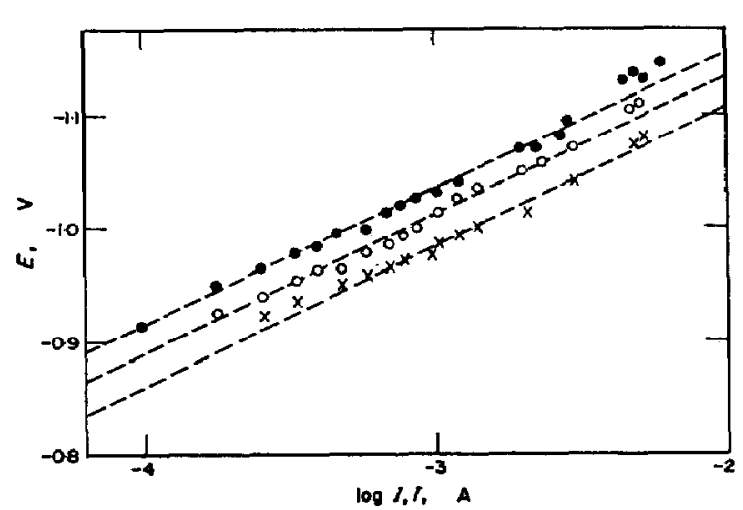

Fig. 3. Semilogarithmic plots of galvanostatic cathodic $E / I$ curves, after correction for the pseudo-ohmic polarisation.

$0.1 \mathrm{M} \mathrm{HCl}+0.4 \mathrm{M} \mathrm{LiCl} ; O, 25^{\circ} \mathrm{C} ; 0,35^{\circ} \mathrm{C} ; \times, 45^{\circ} \mathrm{C}$.

impossible to obtain experimental information for the calculation of the stoichiometric number.

The polarization limits of $\mathrm{LiCl}$ solutions, as determined polarographically, are shown in Fig. 2. The anodic limit is $+0.40 \mathrm{~V}($ sce $)$ and the cathodic

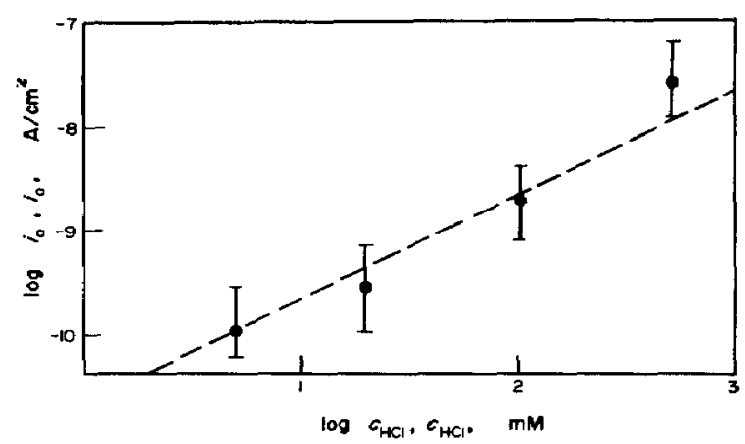

Fig. 4. Log-log plot of $i_{0} v s \mathbf{H C l}$ concentration. Dotted line slope is unity. is $-1.90 \mathrm{~V}($ sce $)$. The slight inflexion of the $E / I$ polaro gram may be due to water reaction[14].

The $i_{0}$ obtained at constant ionic strength exhibits a first-order dependence on the hydrogen chloride concentration, as seen in Fig. 4.

\section{Non-steady measurements}

Semilogarithmic plots of cathode potential decay at current interruptions are shown in Figs. 5 and 6 for different experimental conditions. The plots exhibit a reasonable straight-line portion covering the potential range corresponding to the the Tafelline region of the $E / \log I$ plots. Kinetic parameters derived from these decay curves are indicated in Table 3. $E_{1}$ is the potential at the current interruption, $(\mathrm{d} E / \mathrm{d} \log t)$ is the decay slope in the linear portion of the semilogarithmic plot and $C$ is the apparent electrode differential capacitance at $E_{1}$. The dependence of $C$ on the electrode potential was evaluated from the analysis of the whole decay curve

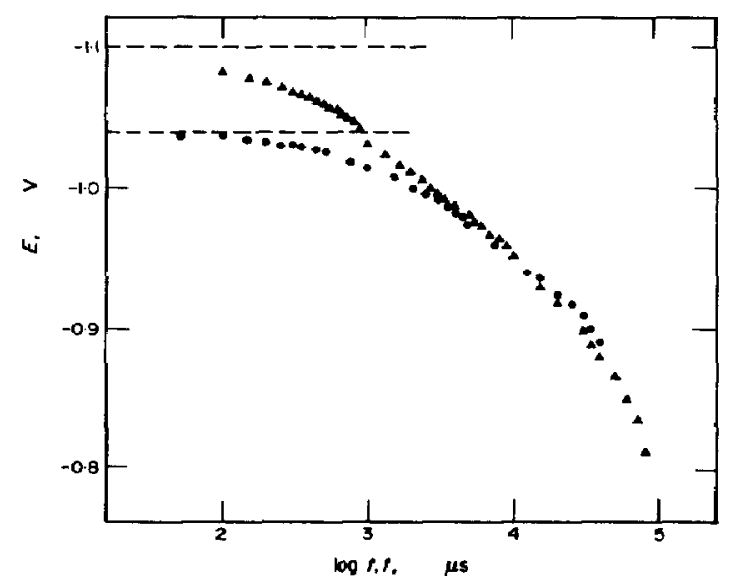

Fig. 5. Semilogarithmic plots of cathodic overvoltage decay at current interruption.

$2 \times 10^{-2} \mathrm{M} \mathrm{HCl}+0.5 \mathrm{M} \mathrm{LiCl} ; 25^{\circ} \mathrm{C}$. 


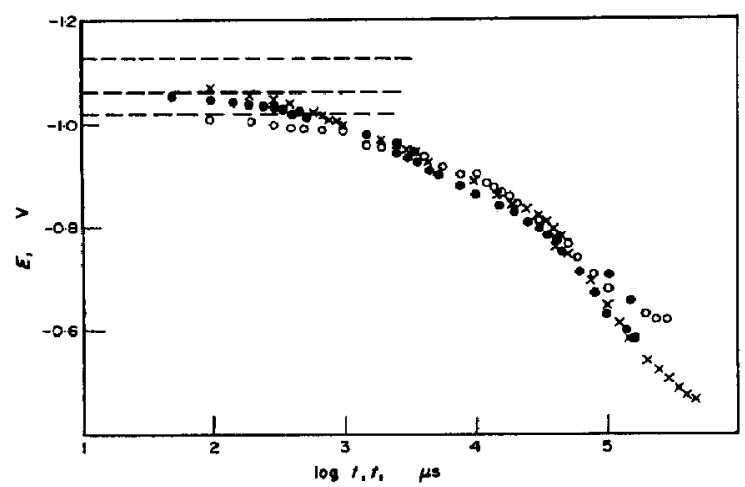

Fig. 6. Semilogarithmic plots of cathodic overvoltage decay at current interruption.

$0.1 \mathrm{M} \mathrm{HCl}+0.4 \mathrm{M} \mathrm{LiCl}$.

Table 3. Parameters derived from cathodic potentialdecay curves at $25^{\circ} \mathrm{C}$

\begin{tabular}{cccc}
\hline $\begin{array}{c}c_{\mathrm{HC}}{ }^{*} \\
\mathbf{M}\end{array}$ & $\begin{array}{c}\left(E-E_{\mathrm{r}}{ }^{\mathrm{T}}\right) \\
\mathrm{V}\end{array}$ & $\begin{array}{c}(\partial E / \partial \log t) \\
\mathrm{V}\end{array}$ & $\begin{array}{c}C \\
\mu \mathrm{F} / \mathrm{cm}^{2}\end{array}$ \\
\hline 0.02 & -0.658 & 0.089 & 6.68 \\
0.02 & -0.688 & 0.091 & 8.52 \\
0.02 & -0.718 & 0.089 & 3.20 \\
0.1 & -0.620 & 0.130 & 6.68 \\
0.1 & -0.635 & 0.130 & 8.06 \\
0.1 & -0.675 & 0.125 & 5.82 \\
0.1 & -0.735 & 0.117 & 3.15 \\
\hline
\end{tabular}

*All solutions $\mu=0.5$ with $\mathrm{LiCl}$.

according to $C=i_{t} /(\mathrm{d} E / \mathrm{d} t)_{t}$, where $i_{t}$ is the current density at time $t$. As seen in Fig. 7, in the potential range -0.8 to $-1.07 \mathrm{~V}(s c e)$ the apparent electrode capacitance fluctuates about an average constant value.

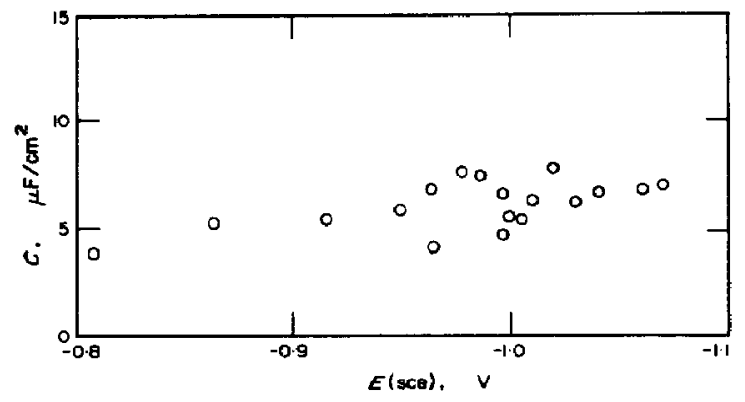

Fig. 7. Electrode capacitance (as calculated from the analysis of the whole decay curve) $v s$ electrode potential. $0.1 \mathrm{M} \mathrm{HCl}+0.4 \mathrm{M} \mathrm{LiCl} ; 25^{\circ} \mathrm{C}$.

\section{Electrode-capacitance measurements}

Figure 8 shows the $\mathrm{C} /$ potential curve of the $\mathrm{Hg}$ electrode in $0.5 \mathrm{M} \mathrm{LiCl}$ solutions at $25^{\circ} \mathrm{C}$ determined by the dme method. The potential of the electrocapillary maximum is also indicated in the figure.

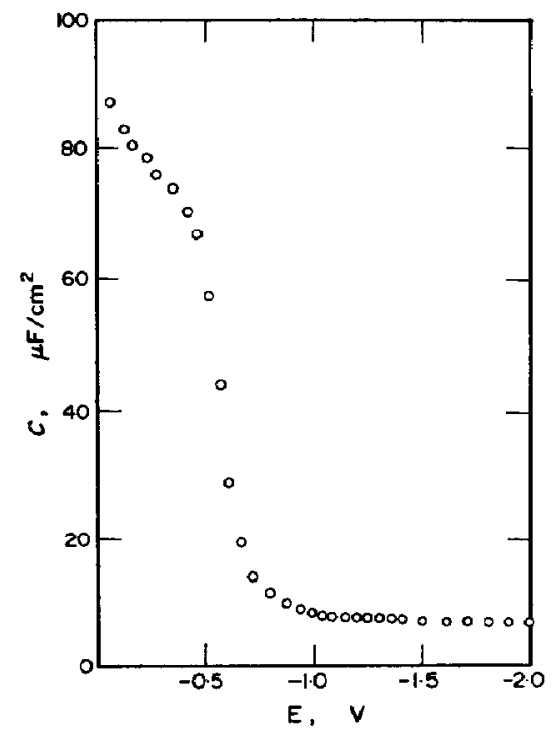

Fig. 8. Electrode capacitance measured by the impedance-bridge method on a dme.

$0.5 \mathrm{M} \mathrm{LiCl}, 25^{\circ} \mathrm{C} ; E_{\mathrm{z}}=-0.4798 \mathrm{~V}(0.1 \mathrm{Nce})$.

The zero-charge parameter was obtained by the mercury-jet method indicated by Grahame[15]. At high chloride-ion concentration, $\mathrm{ca} 0.5 \mathrm{M}$, a reversible potential is set up near the measured pzc (viz $-0.4 \mathrm{~V}$ vs $0.1 \mathrm{~N}$ calomel electrode), which is probably due to an anodic dissolution of the $\mathbf{H g}$ electrode.

\section{DISCUSSION}

Let us first consider the possible structure of the electrical double layer in the potential region where the cathodic evolution of hydrogen from solvated hydrogen ion occurs. The potential dependence of the electrode differential capacitance resembles, as could be expected, that of $\mathrm{NH}_{4} \mathrm{Cl}$ solutions and $\mathrm{KBr}$ solutions in DMSO, the values being nearly coincident with those reported by Payne.[16] The different experimental data on electrode capacitance already mentioned, particularly the low values of $C$ and their independence of potential in the hydrogenion-discharge region, supports the idea of a rather simple double-layer structure at the reaction interface, at least not affected by appreciable accumulation of reaction intermediates. Furthermore, this also explains in a simple way the reasonable coincidence of the Tafel slopes obtained from the rapid $E / \log I$ curves with the decay slopes of the linear portion of the $E / \log t$ plots.

The kinetic parameters obtained for the hydrogen-ion discharge on $\mathbf{H g}$ electrodes employing $\mathrm{HCl}-\mathrm{LiCl}-\mathrm{DMSO}$ solutions indicate a slow reaction rate, as deduced from the exchange $c d$ defined with respect to the pzc. This behaviour is consistent with that of $\mathrm{Hg}$ electrodes in aqueous solutions. 
Therefore the Tafel slope is probably related to the initial electron-transfer step involving the hydrogen-ion-discharge as rate-determining, on condition that the degree of surface coverage by hydrogen atoms is practically zero. The second step should occur under quasi-equilibrium conditions, and it may be either the chemical desorption of hydrogen atoms yielding hydrogen molecules or their electrodic desorption. In this case the transfer coefficient, $\alpha$, is simply equal to the symmetry factor $\beta,(\alpha=\beta=$ $0.5)$. The rate equation is then

$$
i=2 F k_{1} c_{\mathrm{H}}+\exp \left[\frac{-F\left(E-E_{z}\right)}{2 R T}\right],
$$

where $k_{1}$ is the formal specific rate constant for the initial electron transfer step, $c_{\mathrm{H}}+$ is the hydrogen-ion concentration at the reaction interface, $E$ is the electrode potential and $E_{z}$ is the potential of zero charge.

In the presence of the supporting electrolyte, the potential drop from the outer Helmholtz plane to the solution will tend to zero; therefore, if the reference potential (either the $p z c$ or the initial rest potential) does not depend on the concentration of hydrogen ion, (2) implies the first-order dependence found between $i_{0}$ and $c_{\mathrm{H}^{+}}$, instead of the one-half order expected for the corresponding reaction mechanism in water, the hydrogen electrode being taken as reference[17]. As a consequence of the abovementioned assumptions, results obtained for $\mathrm{HCl}-$ DMSO solutions, in the absence of supporting electrolyte, although included in the same plot (Fig. 4) are not directly comparable to the other results. The thermodynamics of $\mathrm{HCl}$ and $\mathrm{LiCl}$ solutions, as far as the corresponding activity coefficients are concerned, are fairly similar, $[12,18,19]$ although no sound arguments are available to decide about structural changes in the DMSO electrical double layer when passing from $\mathrm{Li}^{+}$ion to $\mathrm{H}^{+}$(solvated) ion.

The experimental activation energy, at $\left(E-E_{\mathrm{zpc}}\right)$ $=0$, should in consequence be related to the activation energy of the rate-determining step. Its average value, calculated from the temperature dependence of the $i_{0}$ values reported in Table 2 , is $15.8 \pm 3$ $\mathrm{kcal} / \mathrm{mole}$. This figure must increase with cathodic overvoltage in the way predicted by (2). However, as the error of the activation energy is rather large, no additional kinetic information can be derived from it.
In conclusion, the mechanism for the hydrogenevolution reaction on $\mathrm{Hg}$ in $\mathrm{HCl}-\mathrm{DMSO}$ solutions is probably related to an initial proton-discharge ratedetermining step followed by electrodic desorption. Formally it corresponds to the reaction mechanism established for the reaction on $\mathrm{Hg}$ cathodes in acid aqueous solutions.

Acknowledgement-This work was part of the research program of INIFTA, sponsored by the Universidad Nacional de La Plata, the Consejo Nacional de Investigaciones Científicas y Técnicas of Argentina and the Comisión de Investigaciones Científicas de la Provincia de Buenos Aires.

\section{REFERENCES}

1. K. Vetter, Electrochemical Kinetics, p. 538. Academic Press, New York (1967).

2. I. M. Kolthoff and T. B. Reddy, J. electrochem. Soc. 108, 980 (1961).

3. C. Papon and J. Jacq, Bull. Soc. chim. Fr, 13 (1965).

4. J. Courtot-Coupez and M. Le Démézet, Bull. Soc. chim. Fr. 4744 (1967).

5. J. A. Olabe and A. J. Arvía, Electrochim. Acta 14, 785 (1969).

6. J. A. Olabe and A. J. Arvía. Electrochim. Acta 15, 1685 (1970).

7. D. Posadas, J. J. Podestá and A. J. Arvía, Electrochim. Acta 15, 1225 (1970).

8. A. Delgado, D. Posadas and A. J. Arvía, Electrochim. Acta in press.

9. A. de Béthune, J. Am. chem. Soc. 71, 1556 (1949).

10. P. Delahay, New Instrumental Methods in Electrochemistry, Interscience, New York (1966).

11. G. Paus and D. Posadas, An. Soc. cient. Argent., 192, 239 (1971).

12. J. A. Bolzan and A. J. Arvía, Electrochim. Acta 15, 39 (1970)

13. J. O'M Bockris, R. Parsons and H. Rosenberg, Trans. Faraday Soc. 47, 766 (1951).

14. V. Gutmann and G. Schoeter, Z. anal. Chem. 5, 339 (1959).

15. D. C. Grahame, M. Poth and J. Cummings, J. Am. chem. Soc. 74, 4422 (1952).

16. R. Payne, J. Am. chem. Soc. 89, 489 (1967).

17. B. E. Conway, Theory and Principles of Electrode Process. Ronald, New York (1965).

18. W. H. Smyrl and C. W. Tobias, J, electrochem. Soc. 115,33 (1968).

19. D. R. Cogley and J. N. Butler, J. phys. Chem. 72, 1017 (1968). 